\title{
A Combined Forward Osmosis and Membrane Distillation System for Sidestream Treatment
}

\author{
Taqsim Husnain', Baoxia $\mathrm{Mi}^{2}$, Rumana Riffat ${ }^{1}$ \\ ${ }^{1}$ Department of Civil and Environmental Engineering, George Washington University, Washington DC, USA \\ ${ }^{2}$ Department of Civil and Environmental Engineering, University of Maryland, Maryland, USA \\ Email: taqsim14@yahoo.com
}

Received 11 July 2015; accepted 19 September 2015; published 22 September 2015

Copyright (C) 2015 by authors and Scientific Research Publishing Inc.

This work is licensed under the Creative Commons Attribution International License (CC BY).

http://creativecommons.org/licenses/by/4.0/

(c) (i) Open Access

\begin{abstract}
Separate treatment of high-nutrient sidestream is an efficient and cost effective way to decrease the loading on the main plant, resulting in lower effluent nutrient concentration. This study investigated the use of a combined forward osmosis-membrane distillation (FO-MD) system for the removal of nitrogen present in high concentration in sidestream from anaerobic digestion process. The combined system was able to achieve almost $100 \%$ rejection of solids and acetic acid, and more than $98 \%$ rejection of $\mathrm{NH}_{3}-\mathrm{N}$ from the sidestream. The high rejection of $\mathrm{NH}_{3}-\mathrm{N}$ was mainly achieved by the FO process. The solids in the feed solution contributed to fouling problem in both FO and MD, resulting in significant decline in flux. However, $76 \%$ or higher flux recovery was achieved for FO membrane by cleaning with tap water. We observed that flux recovery was due to removal of solids from the membrane surface by the cleaning process. FO membrane also demonstrated excellent performance for continuous operation when cleaned for $15 \mathrm{~min}$ in every $24 \mathrm{~h}$ interval. Overall, the combined FO-MD system was found to be an effective solution for treatment of nutrient rich sidestream.
\end{abstract}

\section{Keywords}

Forward Osmosis, Membrane Distillation, Sidestream Treatment, Nutrient Removal

\section{Introduction}

Deteriorating water quality and declining health of water bodies around the world have imposed strict regulations of nutrient discharge for the wastewater treatment plants. To comply with the regulations, treatment plants are increasingly considering sidestream treatment for anaerobic digester effluent and dewatering flows; as an 
economical means to reduce capital and operating costs, as well as a mechanism to fortify the performance of the main plant [1]. A sidestream is any process flow resulting from the treatment of biosolids that flows back into the liquid treatment train. Typically, the treatment objective is to remove nutrients [2]. Sidestream treatment is often economical due to the relatively low volume and high concentration of nutrients present. The sidestream flow is about one percent of the forward flow; however, sidestream return accounts for 15 to 30 percent of the total nitrogen load on the process [3]. A lower effluent nutrient concentration can be achieved with separate sidestream treatment by reducing the loading on the main process.

Researchers have studied a number of physico-chemical and biological treatment processes for sidestream nutrient removal. One option is steam stripping, which involves removing the ammonia from solution in gaseous form at high temperatures. Since ammonia gas is a hazardous air pollutant, the facility could be regulated by the U.S. Environmental Protection Agency (EPA), depending on the quantity of ammonia discharged into the atmosphere [4]. Ion exchange was used to achieve 90\% removal of ammonia, although the efficiency reduced significantly with subsequent regeneration of the media [5]. Several biological treatment processes have been developed to remove nitrogen in high concentration sidestream from biosolids processing-SHARON, ANAMOX, and InNitri [6]. DCWater and its program manager partners developed the MAUREEN process to allow for integration of the state of the art in sidestream treatment within a single, highly flexible process configuration [1]. However, the sidestream treatment of filtrate from anaerobic digestion operations using most conventional aerobic nitrification followed by denitrification offers many challenges such as unionized ammonia toxicity to ammonia oxidizing bacteria (AOB), high oxygen demand due to high $\mathrm{NH}_{3}-\mathrm{N}$ loading and low $\mathrm{COD} / \mathrm{N}$ ratio in the filtrate [7].

Advanced membrane technologies like nanofiltration (NF), reverse osmosis (RO), forward osmosis (FO) and membrane distillation (MD) have showed great potential for sustainable wastewater treatment and reuse. Recently, a number of researches investigate the feasibility of these membrane processes for dewatering and nutrient removal from sidestream. Combined forward osmosis/reverse osmosis (FO/RO) process was used to exhibit high water flux and high nutrient rejection and achieved sustainable flux over an extended period [8]. Ref. [9] evaluated the dewatering performance of forward osmosis (FO) and achieved around $96 \%$ of $\mathrm{NH}_{4}^{+}-\mathrm{N}, 98 \%$ of $\mathrm{PO}_{4}^{3-}$-P and $99 \%$ of dissolved organic carbon removal in sludge. The feasibility of applying a forward osmosis dewatering process for nutrient recovery of source-separated urine was studied, and observed 50\% - 80\% rejection of ammonium and more than 90\% rejection of phosphate [10]. A hybrid forward osmosis-nanofiltration (FO/NF) process was designed with EDTA sodium salt as draw solution and achieved removal efficiency of approximately $97 \%$ of $\mathrm{NH}_{4}^{+}-\mathrm{N}, 90 \%$ of $\mathrm{NO}_{3}-\mathrm{N}, 97 \%$ of $\mathrm{NO}_{2}^{-}-\mathrm{N}$ and $99 \%$ of $\mathrm{PO}_{4}^{3-}-\mathrm{P}[11]$.

Forward osmosis (FO) is an osmotic process that uses semi-permeable membrane to achieve separation. One problem that deters the widespread application of FO, when used as a stand-alone process to treat water, is the lack of suitable draw solution that can generate high osmotic pressure, while the draw solutes can be removed efficiently and completely from the diluted draw solution [12]. Membrane distillation (MD) is a thermally driven separation process where water vapor is transported through hydrophobic micro-porous membrane via temperature gradient induced vapour pressure. MD can be successfully combined with FO to recover its draw solution [13]. The feasibility of a FO-MD hybrid process with digested sludge centrate was investigated in Ref. [14]; however, the focus of the study was to evaluate the potential for recovery of phosphorus from struvite precipitation.

In this study, FO was used to reject the nutrients (ammonia nitrogen) from the sidestream and also act as a pre-treatment barrier to reduce or eliminate MD fouling. MD helped recover draw solutes for continuous FO operation. The combined forward osmosis-membrane distillation (FO-MD) system has a great potential of being used for wastewater treatment. The objective of this study is to investigate the potential application of a combined FO-MD system for the removal of nitrogen in high concentration sidestream from anaerobic digestion process. Lab scale studies were conducted to evaluate the effect of solids on the membrane surface, rejection of solids, ammonia nitrogen and acetic acid from sidestream, and reusability of the membrane materials for continuous operation.

\section{Materials and Methods}

\subsection{Membrane Modules}

The forward osmosis (FO) membrane was provided by Hydration Technology, Inc. (Albany, OR). The membrane had an asymmetric structure and made of Cellulose Triacetate (CTA) with embedded polyester screen 
support. The maximum operating temperature was $160^{\circ} \mathrm{F}\left(71^{\circ} \mathrm{C}\right)$, maximum transmembrane pressure was $10 \mathrm{psi}$ and operating $\mathrm{pH}$ range was 3 to 8 , according to the manufacturer. The membrane distillation (MD) membrane was asymmetric polypropylene (PP) membrane. It composed of pure polypropylene and offer broad chemical compatibility allowing its use with aqueous and organic solvent samples. It was obtained from GE Osmonics (Minnetonka, MN). The effective area for both FO and MD membranes were $20.02 \mathrm{~cm}^{2}$ in the membrane cell.

The forward osmosis (FO) membrane module consisted of a custom-built cross-flow membrane cell with two channels for feed and draw solutions. Feed was the wastewater and draw was $1 \mathrm{M} \mathrm{NaCl}$ solution. The water transfer took place across the FO membrane due to the osmotic pressure gradient between the feed and draw solutions, and weight changes in the draw solution were monitored by a computer to record the FO flux. Because pure water was transported from feed to draw by the FO process, the volume of the feed tank decreased and the volume of draw solution increased over time. Two variable speed gear pumps (Micropump, Vancouver, WA) were used to generate cross-flows, forming separate closed loops for the feed and draw solutions. A constant cross-flow rate of $0.4 \mathrm{~L} / \mathrm{min}$ was maintained among the two loops using general purpose acrylic flow-meter (Cole-Parmer, Vernon Hills, IL). The feed solution was completely mixed by a stirrer (Corning, Tewksbury, MA) to avoid settling of particles. The temperature of the feed and draw solutions were maintained at room temperature $\left(20^{\circ} \mathrm{C} \pm 1^{\circ} \mathrm{C}\right)$ by using a water bath (Neslab, Newington, $\left.\mathrm{NH}\right)$. The configuration of the membrane distillation (MD) system was similar to the FO system. The two channels in the MD system were feed, which was the wastewater, and permeate, which was purified water. The feed was operated at an elevated temperature of $50^{\circ} \mathrm{C} \pm 1{ }^{\circ} \mathrm{C}$, while the permeate was maintained at room temperature $\left(20^{\circ} \mathrm{C} \pm 1^{\circ} \mathrm{C}\right)$. Temperature gradient between the two channels transported the water vapor from feed to permeate, which then became condensed by the low temperature permeate solution. Eventually the feed volume reduced and the permeate volume increased by the MD process. Because the feed was operated at an elevated temperature, heavy-duty PTFE/PFA flowmeter (Cole-Parmer, Vernon Hills, IL) was used. In the investigation of combined FO-MD system, draw solution of the FO system was used as a feed in the MD system. The schematic diagrams of the FO and MD setups are shown in Figure 1.

\subsection{Anaerobic Digester Setup}

A batch anaerobic digester was constructed of high density polyethylene (HDPE) 25 L brewer tanks (Hobby Beverage Equipment Company, Temecula, CA). The digester was covered with aluminium foil and temperature adjustable heating tape (Thermolyne, Columbia, MD) was placed on top of the foil. The aluminium foil was used to ensure even heat distribution to the digesters and to provide protection from the heating tape so that physical failure of the polyethylene would not occur. The temperature of the digester was maintained at $35^{\circ} \mathrm{C}$.

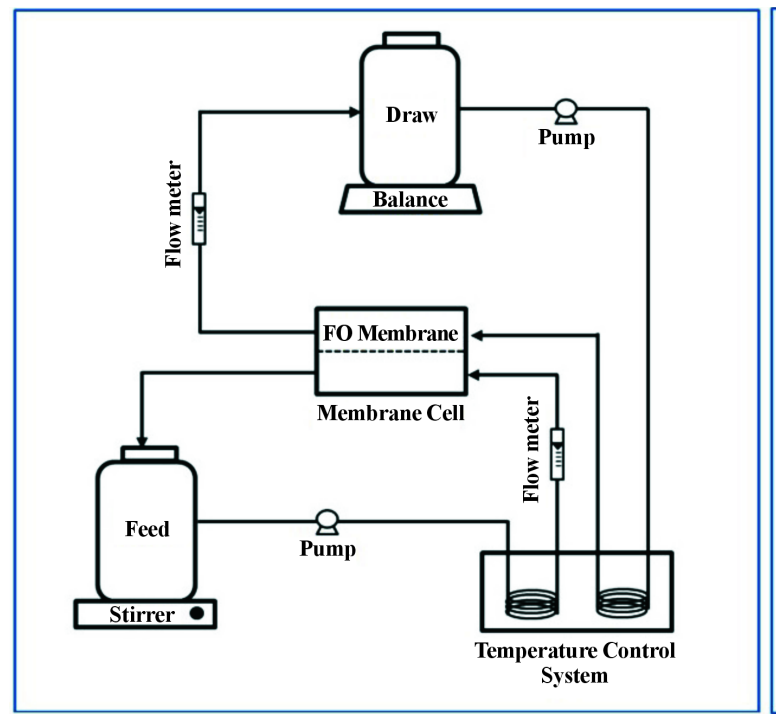

(a)

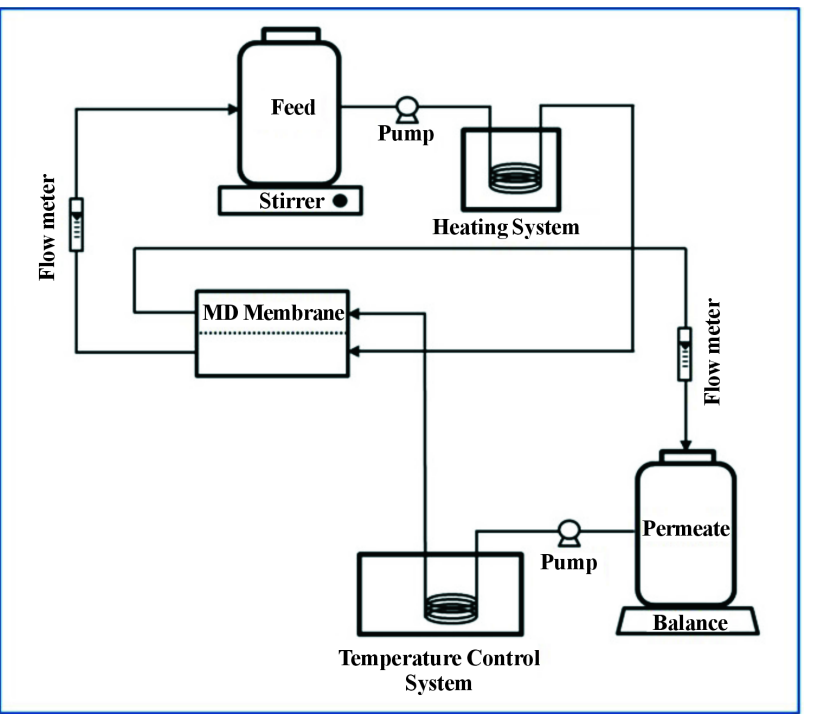

(b)

Figure 1. Schematic diagrams of the (a) FO and (b) MD membrane systems. 
Gas mixing was applied to the anaerobic digester by circulating the headspace gas to the bottom of digesters using a $600 \mathrm{rpm}$ modular drive peristaltic pump (Cole-Parmer, Vernon Hills, IL). The digester was equipped with a gas collection flask and Wet Tip gas meter (Nashville, TN) to measure total gas volume production. Figure 2 shows the laboratory setup of the $35^{\circ} \mathrm{C}$ anaerobic digester system.

The anaerobic digester system was started up with seed sludge from Alexandria Renew Wastewater Treatment Plant in VA. Seed sludge is beneficial due to abundant presence of useful microorganisms such as methane formers and acid formers bacteria. After approximately 3 days of seed feeding, the digester system was fed with raw municipal sludge collected from Blue Plains Advanced Wastewater Treatment Plant (AWTP) in Washington DC. Nitrogen gas $\left(\mathrm{N}_{2}\right)$ was purged for 2 - 3 min to mix the digester before collecting uniform and homogenous effluent and providean anaerobic condition within the digester.

\subsection{Feed Preparation}

The effluent collected from the digester was dewatered by centrifuge using AccuSpin ${ }^{\mathrm{TM}} 400$ (Fisher Scientific, Pittsburg, PA) at 4000 RPM for 10 min. The supernatant was diluted with tap water to obtain the desired concentration of 200 to $2000 \mathrm{mg} / \mathrm{L}$. This centrifuged supernatant was used as feed solution for the FO, MD and combined FO-MD system. The process flow diagram of the feed preparation is illustrated in Figure 3.

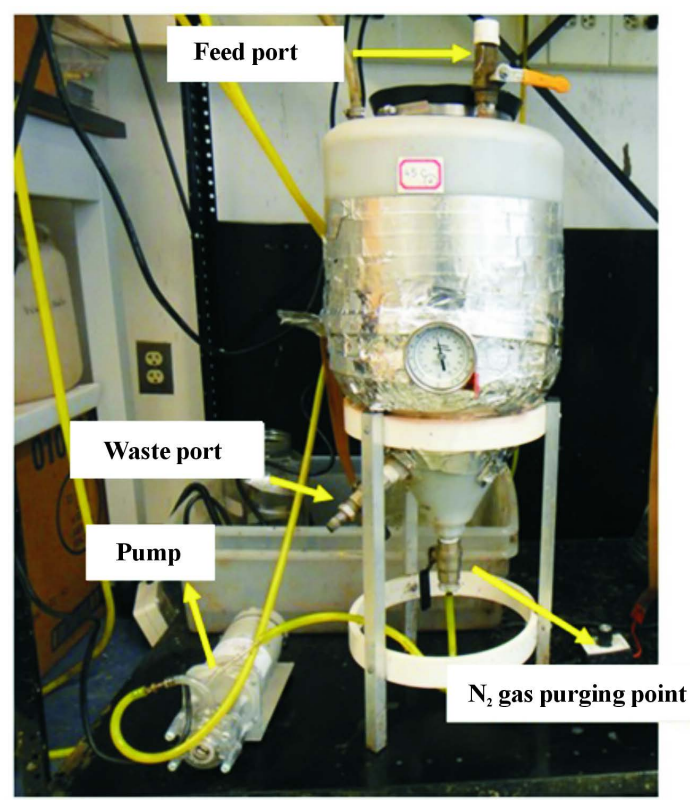

Figure 2. Laboratory setup of anaerobic digestion system.

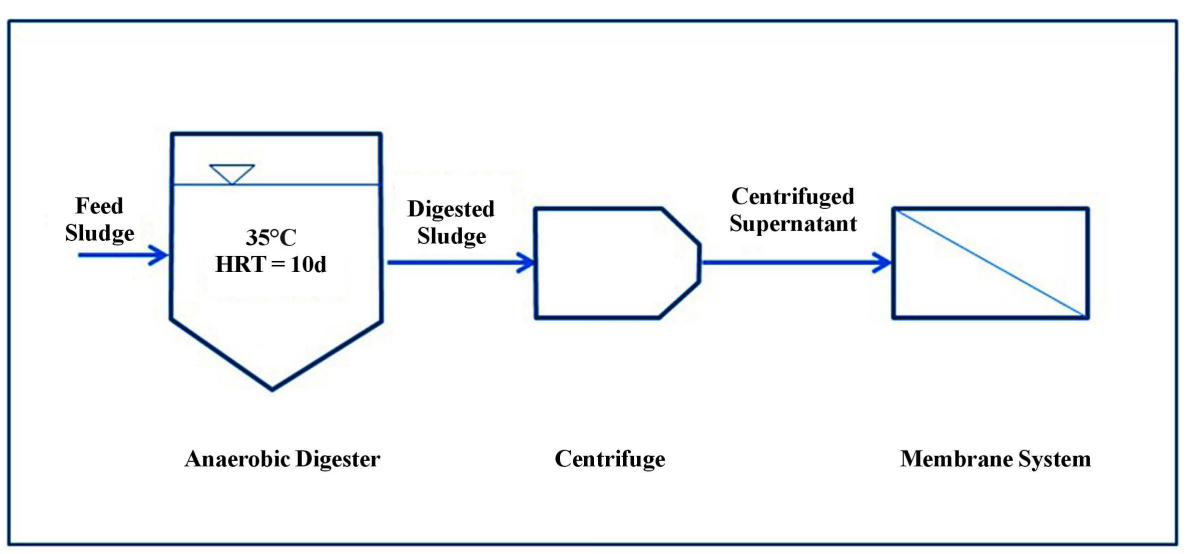

Figure 3. The process flow dirgram of feed preparation. 


\subsection{Experimental Protocols}

The protocol to investigate the fouling effects of solids on the membrane surfaces for FO and MD systems comprised of the following steps. New membranes were placed in the FO system before the experiments. The feed and draw tank were filled with $2 \mathrm{~L}$ solutions. The system was run for $15 \mathrm{~min}$ in closed loop without passing flow through the membrane cell to stabilize the temperature. After $15 \mathrm{~min}$, the feed and draw flows were allowed to the membrane cell by closing the bypass valve. The weight change in the draw tank was continuously monitored by a computer and the water flux through the FO membrane was recorded. For the MD system, the experimental protocol was similar to FO system, except the temperatures of the feed and permeate tanks were maintained at $50^{\circ} \mathrm{C}$ and $20^{\circ} \mathrm{C}$, respectively. To determine the rejection of solids, $\mathrm{NH}_{3}-\mathrm{N}$ and acetic acid, the system was run for $48 \mathrm{~h}$ before collecting the samples for measurements. Total solids (TS) were measured according to the Standard Methods 2540B [15].

Ammonia nitrogen was measured using the titrimetric methods, according to Standard Methods $4500-\mathrm{NH}_{3} \mathrm{C}$. Preliminary distillation in Standard Methods $4500-\mathrm{NH}_{3} \mathrm{~B}$ was followed prior to titration with $0.02 \mathrm{~N} \mathrm{H}_{2} \mathrm{SO}_{4}$ (Fisher Scientific, Pittsburg, PA) [15]. Ammonia measured using this technique is the total ammonia nitrogen (TAN) concentration. Acetic acid was measured using a Shimadzu Gas Chromatograph Model GC-2010 (Shimadzu, Columbia, MD) with flame ionization detector (FID). The rejections of different contaminants were calculated by measuring the concentration in the feed and permeate tanks after continuing the experiment for 48 h. Equation (1) was used for calculating the rejection efficiency, $R$.

$$
R(\%)=\frac{C_{f}-C_{p}}{C_{f}} \times 100 \%
$$

where $C_{f}$ is the initial concentration of the contaminant in the feed tank, and $C_{p}$ is the concentrations of contaminant in the permeate tank after $48 \mathrm{~h}$ of experiment.

In the membrane cleaning experiment, solids deposition on the membrane surfaces was measured and analyzed. For membrane cleaning, the feed and draw (or permeate) tanks were switched with tap water and crossflow rates were increased to $1.0 \mathrm{~L} / \mathrm{min}$. The system was run for $15 \mathrm{~min}$ to allow the increased cross-flow to remove foulants from the membrane surface. Solids deposition and solids removal percentages were calculated by weighing the new membrane, fouled membrane and cleaned membrane. The percentage of flux recovery for the cleaning experiment was calculated using Equation (2).

$$
\text { Flux recovery }(\%)=\frac{J_{v}^{C}-J_{v}^{F}}{J_{v}^{N}-J_{v}^{F}} \times 100 \%
$$

where $J_{v}$ is the water flux in $\left(\mathrm{m}^{3} / \mathrm{m}^{2} \cdot \mathrm{s}\right)$ and superscript $N, F$ and $C$ are used for new membrane, fouled membrane and cleaned membrane, respectively. For the long-term experiments to check the reusability of the FO membrane, the cleaning was performed for 15 min in every $24 \mathrm{~h}$ interval. New feed and draw solutions were put in the tanks before starting the experiments after cleaning.

\section{Results and Discussions}

\subsection{Sidestream Characteristics}

The digester was operated at $35^{\circ} \mathrm{C}$ (mesophilic temperature) with a hydraulic retention time of $10 \mathrm{~d}$. Because the digester was kept completely mixed throughout the study, solids retention time (SRT) of the digester was equal to its hydraulic retention time (HRT). The digester was fed with $5.4 \%$ solids with organic loading rate of 4.22 $\mathrm{kgVS} / \mathrm{m}^{3} \cdot \mathrm{d}$. The performance of the anaerobic digester was continuously monitored and total gas production per day of $31.2 \mathrm{~L} / \mathrm{d}$ was observed with $68.4 \%$ methane content. The digestion process was able to remove $38 \%$ of total solids (TS) and $48 \%$ of volatile solids (VS) from the feed sludge. The effluent from the digester was dewatered by centrifuge at 4000 RPM for $10 \mathrm{~min}$. Different parameters measured for the feed sludge, digested sludge and centrifuged supernatant are summarized in Table 1. The centrifuged supernatant was used as feed to the membrane systems for further treatment.

The supernatant from the centrifuge contained $2020 \mathrm{mg} / \mathrm{L}$ to total solids (TS). To investigate the potential of using coagulants on the centrifuge supernatant, jar test was performed with alum $\left(\mathrm{Al}_{2}\left(\mathrm{SO}_{4}\right)_{3} \cdot 18 \mathrm{H}_{2} \mathrm{O}\right)$ and ferric 
Table 1. Characteristics of raw sludge, digested sludge and centrifuged supernatant.

\begin{tabular}{ccccc}
\hline Parameters & Units & Raw sludge & Digested sludge & $\begin{array}{c}\text { Centrifuged } \\
\text { supernatant }\end{array}$ \\
\hline $\mathrm{pH}$ & - & 6.14 & 7.36 & 8.09 \\
Total solids (TS) & $\mathrm{mg} / \mathrm{L}$ & 53,900 & 33,400 & 2020 \\
Volatile solids (VS) & $\mathrm{mg} / \mathrm{L}$ & 42,180 & 22,130 & 630 \\
Total COD & $\mathrm{mg} / \mathrm{L}$ & 53,684 & 34,759 & 20,500 \\
Soluble COD & $\mathrm{mg} / \mathrm{L}$ & 10,751 & 2300 & 2215 \\
Ammonia (NH $-\mathrm{N})$ & $\mathrm{mg} / \mathrm{L}$ & 281 & 1519 & 1485 \\
Acetic acid & $\mathrm{mg} / \mathrm{L}$ & 1598.1 & 96.4 & 91.7 \\
Propionic acid & $\mathrm{mg} / \mathrm{L}$ & 1040.8 & 48.4 & 44.0 \\
Alkalinity & $\mathrm{mg} / \mathrm{L}$ as CaCO & 3342 & 8428 & 5907 \\
\hline
\end{tabular}

chloride $\left(\mathrm{FeCl}_{3}\right)$. The dosages of coagulants were varied from $10 \mathrm{mg} / \mathrm{L}$ to $80 \mathrm{mg} / \mathrm{L}$ in the standard jar test apparatus to reduce the amount of solids. However, it was found to be ineffective in reducing solids content indicated by the final turbidity value and visual observations. The higher dosage of ferric chloride actually increased the final turbidity in some cases. The difficulties in reducing the total solids from the centrifuged supernatant might be due to the fact that the organic contents were not in particulate form, but in the form of emulsion and thereby coagulation-flocculation process was ineffective.

\subsection{Effect of Solids on FO and MD Membranes}

The sidestream characteristics are highly variable and depend on many factors such as influent composition, treatment process, equipment performance, chemical use and point of applications. Based on different liquid treatment or sludge handling processes, the total solids present in the sidestream varies largely, from $50 \mathrm{mg} / \mathrm{L}$ to $20,000 \mathrm{mg} / \mathrm{L}$ [16]. In order to investigate the variability of the total solids on membrane processes, the centrifuged supernatant were diluted with tap water and used as feed for both FO and MD systems. The feed solution concentrations were varied from $200 \mathrm{mg} / \mathrm{L}$ to $2000 \mathrm{mg} / \mathrm{L}$. The effects of solids on FO and MD membranes are presented in Figure 4.

For both FO and MD membranes, the flux decline is proportional to the amount of solids present in the feed. The higher amount of solids caused membrane fouling faster and resulted in faster flux decline. To compare the effect of solids between FO and MD membranes, the percentages of flux decline were measured from the initial flux after $20 \mathrm{~h}$ for both cases and presented in Table 2. The results showed that for feed solutions with different solids content, flux decline in FO membranes were much lower than that of MD. The initial fluxes for FO membrane were proportional to the solids content in the feed. This is understandable as higher amounts of solids in the feed increased the feed concentration, thereby reduced the osmotic pressure difference across the membrane surface and resulted in lower initial flux. On the other hand, initial fluxes for MD membranes were relatively constant because the partial vapor pressure of water is only minimally affected by increased concentration in the feed [17]. Overall, the fouling effect was found to be more severe in MD membrane as compared to FO membrane.

\subsection{Rejection of Contaminants}

Centrifuged supernatants from the anaerobic digester, with total solids content of $2020 \mathrm{mg} / \mathrm{L}$, caused significant fouling in both FO and MD membranes. Therefore feed solids concentration of $1000 \mathrm{mg} / \mathrm{L}, 400 \mathrm{mg} / \mathrm{L}$ and 200 $\mathrm{mg} / \mathrm{L}$ were used in the rejection experiment. The rejection of total solids, $\mathrm{NH}_{3}-\mathrm{N}$ and acetic acid were measured for the FO, MD and combined FO-MD system.

The centrifuged effluent from anaerobic digester contained approximately $2020 \mathrm{mg} / \mathrm{L}$ of total solids, 1485 $\mathrm{mg} / \mathrm{L}$ of $\mathrm{NH}_{3}-\mathrm{N}$ and $92 \mathrm{mg} / \mathrm{L}$ of acetic acid. The organic contents in the solution were in the form of emulsion and could not be further reduced by using coagulant like alum or ferric chloride. However, the combined FO-MD 


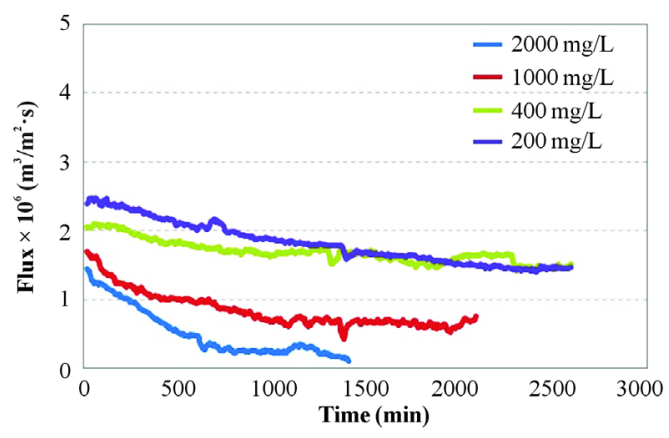

(a)

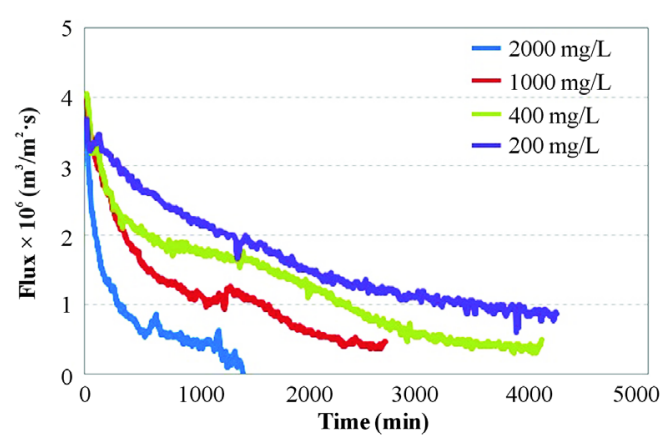

(b)

Figure 4. Effects of total solids on (a) FO and (b) MD membrane systems.

Table 2. Flux $\left(\times 10^{6} \mathrm{~m}^{3} / \mathrm{m}^{2} \cdot \mathrm{s}\right)$ decline for FO and MD membranes.

\begin{tabular}{|c|c|c|c|c|c|c|}
\hline \multirow{2}{*}{$\begin{array}{l}\text { Total solids in } \\
\text { feed (mg/L) }\end{array}$} & \multicolumn{3}{|c|}{ FO membrane } & \multicolumn{3}{|c|}{ MD membrane } \\
\hline & Initial flux & Flux after $20 \mathrm{~h}$ & \% Decline & Initial flux & Flux after 20 h & \% Decline \\
\hline 2000 & 1.37 & 0.35 & $74.4 \%$ & 4.00 & 0.33 & $91.8 \%$ \\
\hline 1000 & 1.71 & 0.78 & $54.5 \%$ & 4.08 & 1.13 & $72.2 \%$ \\
\hline 400 & 2.07 & 1.63 & $21.0 \%$ & 4.10 & 1.83 & $55.3 \%$ \\
\hline 200 & 2.37 & 1.88 & $20.5 \%$ & 3.90 & 2.17 & $44.5 \%$ \\
\hline
\end{tabular}

system was able to achieve almost $100 \%$ rejection of total solids. For the rejection of $\mathrm{NH}_{3}-\mathrm{N}$, FO-MD system was more than $98 \%$ efficient when the solids content in the feed was less than $1000 \mathrm{mg} / \mathrm{L}$, as shown in Table 3. Investigating the rejection for FO and MD separately revealed that the higher rejection in the FO-MD system was mainly achieved due to the FO process. For MD, the rejection was approximately $62 \%-72 \%$. The poor rejection is due to the fact that higher solids (organic content) in the feed caused wetting problem in the MD and allowed the contaminants to pass through. The volatile nature of the contaminants at $\mathrm{pH} 8$ can also contribute to the rejection efficiency, as MD process allowed volatile matters to pass through.

High rejection (>98\%) of acetic acid was also obtained by both FO and MD processes. The pH of the centrifuged supernatants was higher than 8.0. At this $\mathrm{pH}$, the acetic acid was mainly in the form of negatively charged acetate ion in the solution ( $\mathrm{pKa}$ value of 4.7). The higher $\mathrm{pH}$ have increased the negative charged surface density of the membranes, which increased the electrostatic interaction between the membrane surface and negative charged acetate ion, thus resulting in high rejection. The combined FO-MD process achieved almost $100 \%$ rejection of acetic acid.

\subsection{Membrane Cleaning for Continuous Operations}

Fouling in MD membrane was significantly high while treating sidestream from anaerobic digester. In the combined FO-MD system, FO was primarily used to treat the sidestream, while MD was regenerating the draw solution. Therefore, fouling was mostly associated with FO.

FO process is an ambient pressure operation. Foulants in FO membrane are loosely attached to the membrane surface and can be cleaned with tap water [18]. For the cleaning experiments, 15 min cleaning were performed after running the tests for $1 \mathrm{~d}$. Figure 5 showed the measurement of weights for new membranes, fouled membranes and cleaned membranes with different feed concentrations. Table 4 presents the solids removal and flux recovery from the cleaning experiments. The results showed that $44 \%$ to $60 \%$ of the solids from membrane surface were removed by cleaning with tap water for $15 \mathrm{~min}$, which resulted in a flux recovery of as high as $84 \%$. The results showed great potential of reusing the FO membrane with continuous cleaning, which can significantly reduce the operating cost of the process.

To investigate the reusability of the FO membrane, $200 \mathrm{mg} / \mathrm{L}$ feed was used for a 4-d experiment with continuous cleaning. Membrane cleaning was performed for 15 min in every 24 h interval. The results in Figure 6 


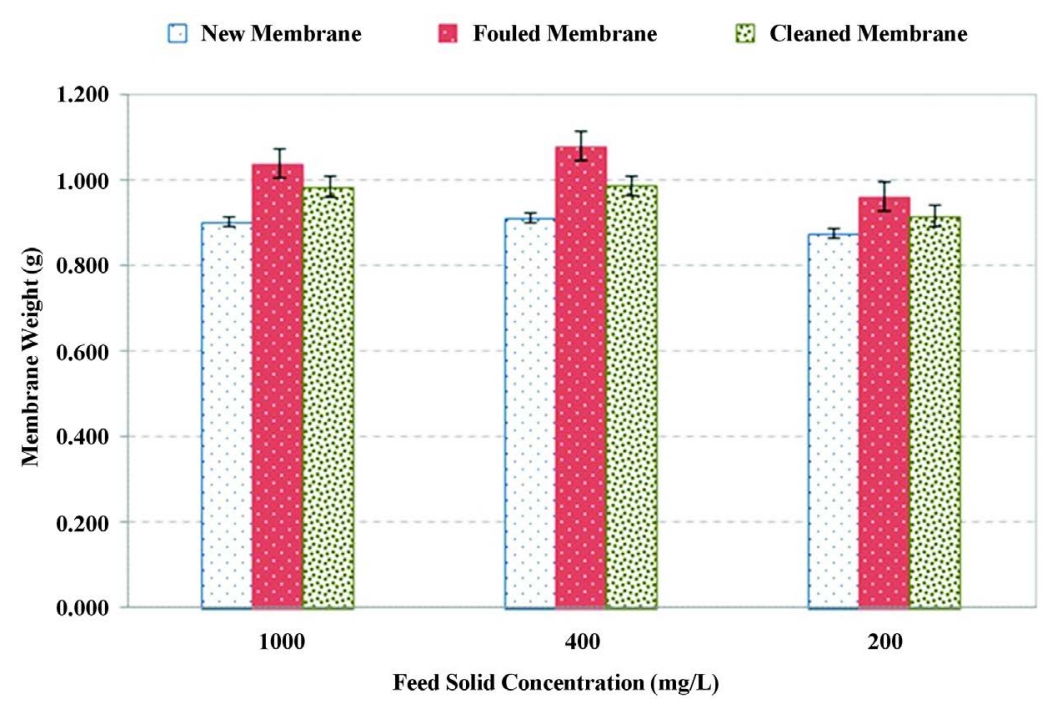

Figure 5. Weight measurements from cleaning experiments in FO.

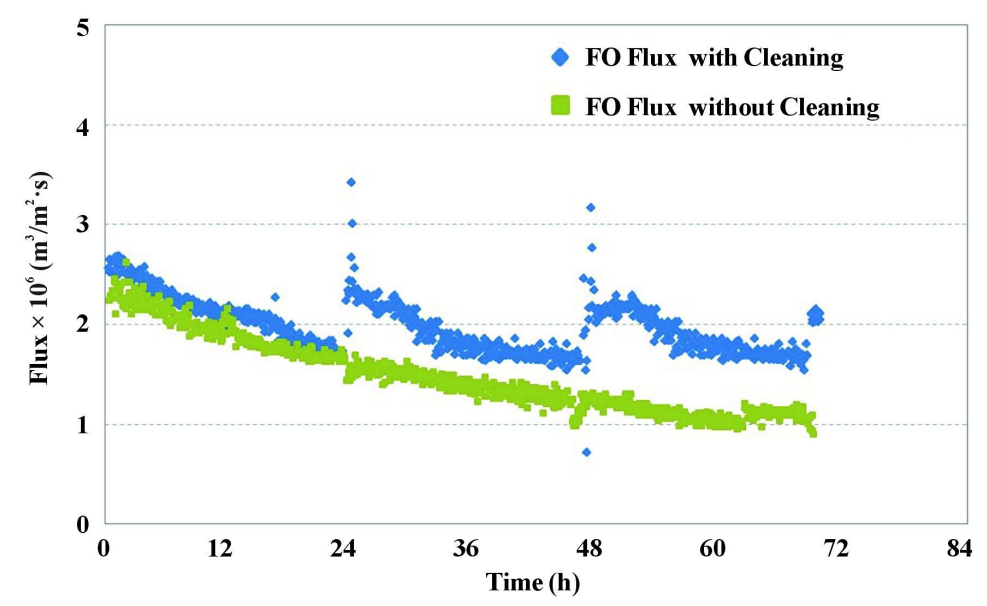

Figure 6. FO membrane flux with and without continuous cleaning.

Table 3. Rejection of $\mathrm{NH}_{3}-\mathrm{N}(\mathrm{mg} / \mathrm{L})$ in combined FO-MD and separate FO and MD systems.

\begin{tabular}{ccccccccccc}
\hline \multirow{2}{*}{$\begin{array}{c}\text { Total solids in } \\
\text { feed (mg/L) }\end{array}$} & \multicolumn{3}{c}{ FO-MD } & \multicolumn{3}{c}{ FO } & \multicolumn{3}{c}{ MD } \\
\hline 1000 & Initial & Final & \% Rejection & Initial & Final & \% Rejection & Initial & Final & \% Rejection \\
400 & 281.1 & 1.12 & $>99.6 \%$ & 302.4 & 3.36 & $98.9 \%$ & 302.4 & 89.6 & $70.4 \%$ \\
200 & 14.08 & $98.6 \%$ & 788.2 & 7.84 & $99.0 \%$ & 788.2 & 291.2 & $63.1 \%$ \\
\hline
\end{tabular}

Table 4. Solids removal and flux recovery for FO membrne.

\begin{tabular}{ccc}
\hline Total solids in feed $(\mathbf{m g} / \mathbf{L})$ & Solids removal (\%) & Flux recovery (\%) \\
\hline 1000 & $59.7 \%$ & $75.8 \%$ \\
400 & $44.8 \%$ & $81.8 \%$ \\
200 & $49.3 \%$ & $83.9 \%$ \\
\hline
\end{tabular}


show that continuous flux recovery can be achieved by cleaning the membrane. The results also demonstrated that percentage flux recovery deteriorated with every cleaning. When comparing the results with a similar experiment without continuous cleaning, the FO membrane performed better in terms of water flux with cleaning. In this case, $961.2 \mathrm{~mL}$ of water was recovered by FO process with cleaning, as compared to $725.1 \mathrm{~mL}$ of water without cleaning, resulting 33\% higher water recovery when the FO membrane was cleaned in every $24 \mathrm{~h}$ interval.

\section{Conclusion}

In this study, a combined forward osmosis-membrane distillation (FO-MD) system was used for the removal of solids, nitrogen and acetic acid in high concentration sidestream generated from lab-scale mesophilic anaerobic digestion process. The system was able to remove $100 \%$ solids from the wastewater, which was difficult by traditional coagulation-flocculation process. The $\mathrm{NH}_{3}-\mathrm{N}$ rejection was more than $98 \%$ in the combined system. It was found that FO system had higher removal efficiency (>99\%) than MD system (63\% - 72\%). The poor removal in the MD system was due to the hydrophobic characteristics of the membrane and volatile nature of the contaminants. Solids present in the sidestream caused significant fouling and flux decline in both FO and MD. However, cleaning the FO membrane with tap water achieved up to $60 \%$ solids removal, which resulted in approximately $84 \%$ flux recovery. The FO membrane also showed great potential for reuse when cleaned at a regular interval. It was found that, 33\% higher water recovery could be achieved when FO membrane was cleaned for $15 \mathrm{~min}$ in every $24 \mathrm{~h}$ interval. In the combined FO-MD system, FO was mainly used for rejection of contaminants from the sidestream and MD was used to regenerate the draw solution. The combined system can be an effective solution for sidestream treatment to achieve low effluent nutrient concentration.

\section{Acknowledgements}

The authors are grateful to the United States Department of State under the Pakistan-US Science and Technology Cooperation Program for partially funding this research. In addition, the authors thank Blue Plains Advanced Wastewater Treatment Plant in Washington, DC, for providing the wastewater samples and Hydration Technology Innovations for providing the FO membrane.

\section{References}

[1] Katehis, D., Murthy, S., Wett, B., Locke, E. and Bailey, W. (2005) Nutrient Removal from Anaerobic Digester SideStream at the Blue Plains AWTP. Proceedings of the Water Environment Federation, WEFTEC, Dallas.

[2] Bilyk, K., Taylor, R., Pitt, P. and Wankmuller, D. (2011) Process and Economic Benefits of Sidestream Treatment. Proceedings of the North Carolina AWWA-WEA Annual Conference, 1-11.

[3] Solley, D. (2000) Upgrading of Large Wastewater Treatment Plant for Nutrient Removal. Churchill Fellowship 2000 Report, The Winston Churchill Memorial Trust of Australia.

[4] Phillips, H.M., Kobylinski, E., Barnard, J. and Wallis-Lage, C. (2006) Nitrogen and Phosphorus-Rich Sidestreams: Managing the Nutrient Merry-Go-Round. Proceedings of the Water Environment Federation's 79th Annual Technical and Educational Conference, Dallas. http://dx.doi.org/10.2175/193864706783763309

[5] Mackinnon, I.D.R., Barr, K., Miller, E., Hunter, S. and Pinel, T. (2003) Nutrient Removal from Wastewaters Using High Performance Materials. Water Science and Technology, 47, 101-107.

[6] Warakomski, A., van Kempen, R. and Kos, P. (2006) Microbiology/Biochemistry of the Nitrogen Cycle Innovative Process Applications. Proceedings of the International Water Association, New Brunswick.

[7] Kotay, S.M., Mansell, B.L., Hogsett, M., Pei, H. and Goel, R. (2012) Anaerobic Ammonia Oxidation (ANAMMOX) for Side-Stream Treatment of Anaerobic Digester Filtrate Process Performance and Microbiology. Biotechnology and Bioengineering, 110, 1180-1192. http://dx.doi.org/10.1002/bit.24767

[8] Holloway, R.W., Childress, A.E., Dennett, K.E. and Cath, T.Y. (2007) Forward Osmosis for Concentration of Anaerobic Digester Centrate. Water Research, 41, 4005-4014. http://dx.doi.org/10.1016/j.watres.2007.05.054

[9] Nguyen, N.C., Chen, S.S., Yang, H.Y. and Hau, N.T. (2013) Application of Forward Osmosis on Dewatering of High Nutrient Sludge. Bioresource Technology, 132, 224-229. http://dx.doi.org/10.1016/j.biortech.2013.01.028

[10] Zhang, J.F., She, Q.H., Chang, V.W.C., Tang, C.Y.Y. and Webster, R.D. (2014) Mining Nutrients (N, K, P) from Urban Source-Separated Urine by Forward Osmosis Dewatering. Environmental Science and Technology, 48, 3386-3394. http://dx.doi.org/10.1021/es405266d 
[11] Hue, N.T., Chen, S.S., Nguyen, N.C., Huang, K.Z., Ngo, H.H. and Guo, W.S. (2014) Exploration of EDTA Sodium Salt as Novel Draw Solution in Forward Osmosis Process for Dewatering of High Nutrient Sludge. Journal of Membrane Science, 455, 305-311. http://dx.doi.org/10.1016/j.memsci.2013.12.068

[12] National Water Commission (2008) Emerging Trends in Desalination: A Review. Waterlines Report Series No. 9, UNESCO, Canberra.

[13] Husnain, T. (2014) Combined Forward Osmosis and Membrane Distillation System for Wastewater Treatment and Reuse. Ph.D. Dissertation, George Washington University, Washington DC.

[14] Xie, M., Nghiem, L.D., Price, W.E. and Elimelech, M. (2014) Toward Resource Recovery from Wastewater: Extraction of Phosphorus from Digested Sludge Using a Hybrid Forward Osmosis-Membrane Distillation Process. Environmental Science and Technology Letters, 1, 191-195. http://dx.doi.org/10.1021/ez400189z

[15] APHA (2012) Standard Methods for the Examination of Water and Wastewater. 22nd Edition, American Public Health Association, Washington DC.

[16] Metcalf and Eddy/EPA (1987) EPA Design Information Report: Sidestreams in Wastewater Treatment Plants. Journal of Water Pollution Control Federation, 59, 54-59.

[17] Martinetti, C.R. (2008) Membrane Contactor Processes for Desalination of Brackish Water Reverse Osmosis Brines. Ph.D. Dissertation, University of Nevada, Reno.

[18] Mi, B. and Elimelech, M. (2010) Organic Fouling of Forward Osmosis Membranes: Fouling Reversibility and Cleaning without Chemical Reagents. Journal of Membrane Science, 348, 337-345. http://dx.doi.org/10.1016/j.memsci.2009.11.021 